\title{
A rodent model of schizophrenia reveals increase in creatine kinase activity with associated behavior changes
}

\author{
Leila Canever, 'Larissa Oliveira, ${ }^{1}$ Renata D'Altoé de Luca, ${ }^{1}$ Paulo T.F. Correa, Daiane de B. Fraga, ${ }^{1}$ Maria Paula Matos, \\ Giselli Scaini, ${ }^{2}$ João Quevedo, ${ }^{1}$ Emílio L. Streck ${ }^{2}$ and Alexandra I. Zugno,**
}

\begin{abstract}
'Laboratório de Neurociências; ${ }^{2}$ Laboratório de Fisiopatologia Experimental and Instituto Nacional de Ciências e Tecnologia Translacional em Medicina (INCT-TM); Programa
\end{abstract} de Pós-Graduação em Ciências da Saúde; Unidade Acadêmica de Ciências da Saúde; Universidade do Extremo Sul Catarinense; Criciúma, SC Brazil

Key words: brain, ketamine, schizophrenia, creatine kinase, behavioral, energy metabolism

\begin{abstract}
Schizophrenia is a debilitating mental disorder characterized by positive (delusions, hallucinations, disorganized speech) and negative (affective flattering, avolition and social withdrawal) symptoms as well as cognitive deficits. The frequency, severity and topography characterize the disorder as heterogeneous, the pathophysiology of schizophrenia is poorly understood. Sub-anesthetic doses of ketamine produce hyperactivity, stereotypy and abnormal social interaction and it is used as a model of schizophrenia. In this study, we induced an animal model by acute sub-anesthetic doses of ketamine and tested different behavioral parameters. We also evaluated the activity of creatine kinase (CK) in brain of rats treated with ketamine. Our results demonstrated that administration of 10,25 and $50 \mathrm{mg} / \mathrm{kg}$ of ketamine induced an increase of covered distance in habituated and non-habituated rats to the behavioral apparatus. Ketamine administration induced significant social deficits and stereotypic behavioral in all doses tested. Finally we evaluated the effect of different doses of ketamine on creatinine kinase (CK) activity and we observed that CK activity is increased inspecific regions of the brain. Our study suggests that our animal model may be used as a model of schizophrenia and that cerebral energy metabolism might be altered in the brain of schizophrenic patients, probably leading to alterations that might be involved in the pathogenesis of schizophrenia.
\end{abstract}

\section{Introduction}

Schizophrenia is a severe psychiatric disorder, it carries a lifetime risk of around $0.5-1 \%$ and its early onset and tendency to chronicity mean that its prevalence is relatively high. The social and economic impact of this illness is enormous and its impact on sufferers and their families can be devastating. ${ }^{1}$ It is a complex disorder with a poorly defined cause. Pathophysiological findings in schizophrenia include an enlarged ventricular system accompanied by an overall reduction in brain volume, with regional decreases in the hippocampus, thalamus and frontal lobes. Neuroimaging and post mortem analyses have demonstrated subtle, but distinct, abnormalities in the schizophrenic brain particularly in the hippocampus and neocortex. ${ }^{2}$ The classical symptoms of schizophrenia include positive symptoms, such as delusions and hallucinations and negative symptoms, such as blunted affect and social withdrawals, but aspects as awareness, orientation, perception, cognitive impairments, affect, thought and language and neurological signs are also important findings in this disease. ${ }^{3}$
In order to understand the pathologic mechanisms found in this disease, animal models have been used. These models are animals prepared that attempt to mimic a human condition of the psychopathology associated with the group of schizophrenia disorders. ${ }^{4}$ Many models have already been described including behavioral models, psychotropic drug-induced locomotor hyperactivity and prepulse inhibition. ${ }^{5-8}$ An animal model using ketamine is widely accepted; it is a dissociative anesthetic, affecting glutamatergic activity via blockade of the $\mathrm{N}$-methil-D-aspartate (NMDA) receptor.? It is already known that ketamine causes individual psychoses in remitted schizophrenic patients and the use of this substance is also used to assess positive and negative symptoms of schizophrenia in healthy volunteers. ${ }^{8}$ These authors also reported that sub-chronically ketamine-treated animals give evidence that ketamine is a useful animal model of schizophrenia. Moreover, Geyer et al. ${ }^{4}$ described in their review that in rats and monkeys, noncompetitive NMDA antagonists, including PCP and ketamine, produce a range of behavioral abnormalities that have important relationships to schizophrenic symptomatology. 


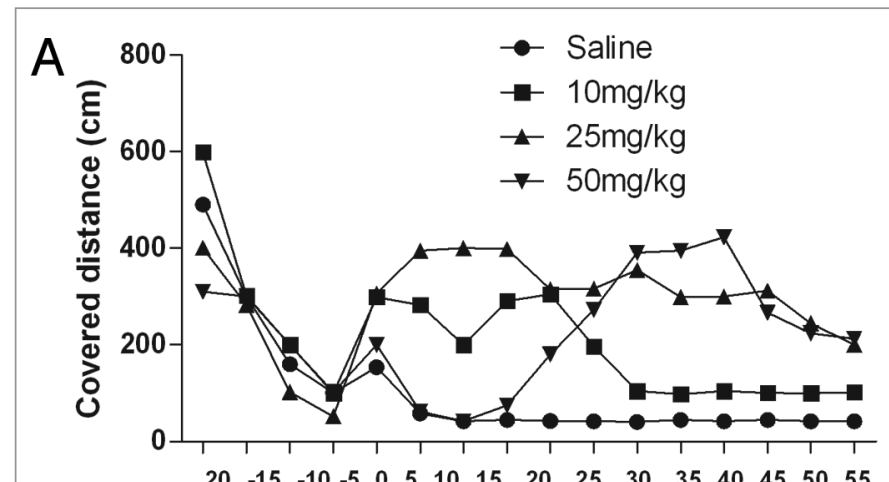

$\begin{array}{llllllllllllllll}20 & -15 & -10 & -5 & 0 & 5 & 10 & 15 & 20 & 25 & 30 & 35 & 40 & 45 & 50 & 55\end{array}$

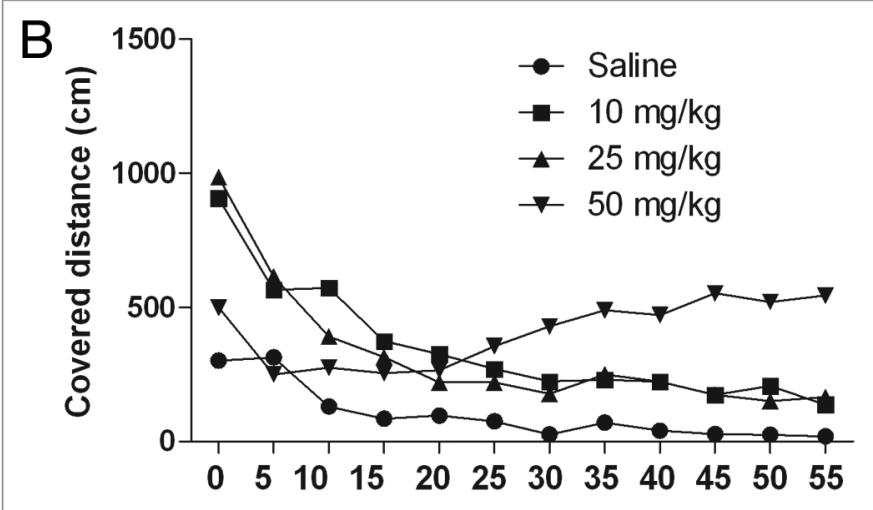

Figure 1. The open-field apparatus was used to assess locomotor activity. Covered distance was measured in open-field test during 60 minutes after acute administration of ketamine (control, 10, 25 and 50 $\mathrm{mg} / \mathrm{kg}$ ). We observed animals wich had 20 minutes habituated in the apparatus (A) and animals that had no this habituated time (B). The distance was analyzed in 5 minute-blocks for 60 minutes. Control group is treated with saline $0.9 \%$. Data were analyzed by ANOVA followed by Tuckey test. *A value of $p<0.05$ was considered significant and different from control. Results were expressed as centimeters (cm).

Disturbs found in brain energy metabolism are important factors that contribute to neuronal damage in patients with schizophrenia. ${ }^{10-15}$ Creatine kinase $(\mathrm{CK})$ is an important enzyme that participates of an important system that maintains the energy homeostasis, this regulation of cell homeostasis is done by isoforms mitochondrial (mtCK) and cytosolic (ctCK) and any alteration in the circuit of creatine-phosphocreatine can be an important step for the neurodegenerative process that leads to the loss neuronal in the brain. ${ }^{16,17}$

Mitochondrial dysfunction with subsequent alteration in respiratory chain complexes is implied in the pathofisiology of schizophrenia. ${ }^{18,19}$ Once the CKmit enzyme acts as ATP energetic reserve, it can acquire a modulatory role to suppress cerebral energy demand. ${ }^{20}$ This cerebral demand is altered in schizophrenia, as well as in other psychiatric disorders. ${ }^{21,22}$

Considering that schizophrenia is a complex psychiatric disorder, we induced an animal model by chronic sub-anesthetic doses of ketamine and test different parameters of behavior rat tasks. It is important to provide new information on the mechanisms involved in the symptoms and development of the disease. Therefore, we also evaluated the effects of sub-anesthetic doses of ketamine on creatine kinase (CK) activity, an enzyme responsible for energy buffering in tissues that use highly rates of energy such as the brain, in prefrontal cortex, hippocampus, cerebellum, striatum and cerebral cortex of animals.

\section{Results}

In this study, we verify the effect of different doses of ketamine in 60 days-old rats in order to evaluate behavioral parameters in an animal model of schizophrenia. Figure 1 shows that habituated rats (A) have a different behavior when compared to nonhabituated groups (B). We observed that the administration of $25 \mathrm{mg} / \mathrm{kg}$ ketamine induced an increase of covered distance in non-habituated group. We also observed an enhanced covered distance in habituated group in all doses tested $\left[\mathrm{F}_{(7,91)}=6.63\right.$; $\mathrm{p}<0.01]$. An increase of rearings at $10 \mathrm{mg} / \mathrm{kg}$ ketamine was observed, either in the habituated or non-habituated groups, when compared to control $\left[F_{(7,92)}=4.63 ; \mathrm{p}<0.01\right]$ (data not shown). In Figure 2 we compared these data to the accumulated covered distance of both groups in all doses tested.

Ketamine administration induced significant social deficits. There was no significant difference in the latency to start the interaction $\left[\mathrm{F}_{(3,34)}=0.203 ; \mathrm{p}=0.87\right]$ (Fig. 3A). However, comparisons revealed significant differences among groups in number of contacts in $50 \mathrm{mg} / \mathrm{kg}\left[\mathrm{F}_{(3,34)}=10.14 ; \mathrm{p}<0.01\right]$ (Fig. 3B) and the amount of time spent engaged in social interaction in all doses tested $\left[\mathrm{F}_{(3,34)}=25.81 ; \mathrm{p}<0.01\right]$ (Fig. 3C).

Next, we examined the stereotypy induced by the administration of ketamine. We showed that all the doses induced stereotypic movements in habituated and non-habituated rats (Fig. 4) $\left[\mathrm{F}_{(7,89)}=12.630 ; \mathrm{p}<0.01\right]$

Finally, it was evaluated the effect of different doses of ketamine on CK activity (Fig. 5). We observed an increase of CK activity caused by the administration of 25 and $50 \mathrm{mg} / \mathrm{kg}$ of ketamine all structures analyzed but hippocampus. In this structure, we observed an increase only when $50 \mathrm{mg} / \mathrm{Kg}$ of ketamine was administrated.

\section{Discussion}

Schizophrenia is a polygenic disorder and the involvement of factors, such as environment and development, complicates the study of the underlying mechanisms. However, there are some characteristic manifestations that mark this disease. The positive symptoms (delusions, hallucinations and disorganization) as well as the negative symptoms (loss of motivation and emotional vibrancy) and also disturbance in cognitive functions and memory are observed in schizophrenic patients. ${ }^{23}$

Ketamine, amphetamine or dopaminergic psycho stimulants have faced validity for the stereotyped behavior induced in humans. ${ }^{4}$ In contrast to amphetamine, which mimics only the positive symptoms of the disease, subanesthetic doses of the NMDA antagonist ketamine have been reported to produce positive and negative symptoms and cognitive impairments consistent with those seen in schizophrenia. These models measure locomotor hyperactivity and have been used extensively to 
characterize the effects of both amphetamine and NMDA in the animals. ${ }^{24}$

It is already known that ketamine is an appropriate drug to induce psychotic behavior; however, there is not a consensus in literature that defines an adequate dose. There are evidences showing that ketamine in very low doses, such as 5, 10 and 15 $\mathrm{mg} / \mathrm{kg}$, could be an anti-depressive agent. ${ }^{25,26}$ To induce locomotor activity and cellular dysfunction it ranges from 10 to 50 $\mathrm{mg} / \mathrm{Kg}^{7,27,28}$ and, in higher doses, ketamine is a potent anesthetic drug. ${ }^{29}$

Previous studies from our group have also showed that acute administration of ketamine $(15 \mathrm{mg} / \mathrm{kg})$ reversed the inhibition of mitochondrial respiratory chain in cerebral cortex and cerebellum, in animals submitted to mild chronic stress. ${ }^{26}$ This study is in agreement with other lines of evidence that affirmed that ketamine promotes a protective effect on cellular energy, maintained glucose metabolism and ATP production. ${ }^{30}$ On the other hand, Rudin et al. ${ }^{31}$ showed that some sub-anesthetic doses of ketamine, ranging from 10 to $40 \mathrm{mg} / \mathrm{kg}$, caused apoptosis, increasing the number of damaged neuron in neonatal mice, confirmed by DNA fragmentation, in cortex and cerebellum.

In the present study, our results showed that ketamine induces hyper-locomotor activity in rats subjected to sub-anesthetic doses. We tested the animals in a 20 minutes habituation period or without habituation. Our results showed differences between doses and habituation and they also demonstrated a hyperlocomotion of these animals when subjected to ketamine. We observed a hypolocomotion in $50 \mathrm{mg} / \mathrm{kg}$ in the first minutes of the analyses and we attributed this to a pre-anesthetic stage of ketamine.

We attributed the effect of habituation an important fact in the hyperlocomotion since we observed that the anxiety may be involved and interfere in the behavioral of the animals. A recent study showed that repeated use of ketamine in weekly intervals may result in neural sensibilization, especially when associated to diverse environmental conditions. ${ }^{6}$ Irufune et al..$^{32}$ demonstrated that ketamine-induced hyperlocomotion is inhibited by the administration benzodiazepinic drugs, once it suppresses dopaminergic neuronal activation in nucleum accubens and striatum.

We also analyzed the social interaction (evident parameter observed in schizophrenic patients) between animals treated and non-treated with ketamine. The study showed that the time spent in social interaction was altered when compared to control groups in all doses tested. In this context, our rats presented an anti-social behavioral, corroborating with the symptoms found in schizophrenia.

Stereotyped behaviors are features of psychiatric disorders such as schizophrenia and obsessive-compulsive disorder, ${ }^{33}$ and it is broadly defined, including a number of types of abnormal movements. We demonstrated that the habituated and non-habituated animals in all ketamine doses tested showed stereotypic movements when compared to controls. Together, our chronic model of administration of ketamine showed an alteration in the behavioral of rats that are in agreement with schizophrenic symptoms.

Although behavioral alterations are important parameters to understand the symptoms found in schizophrenic patients, there

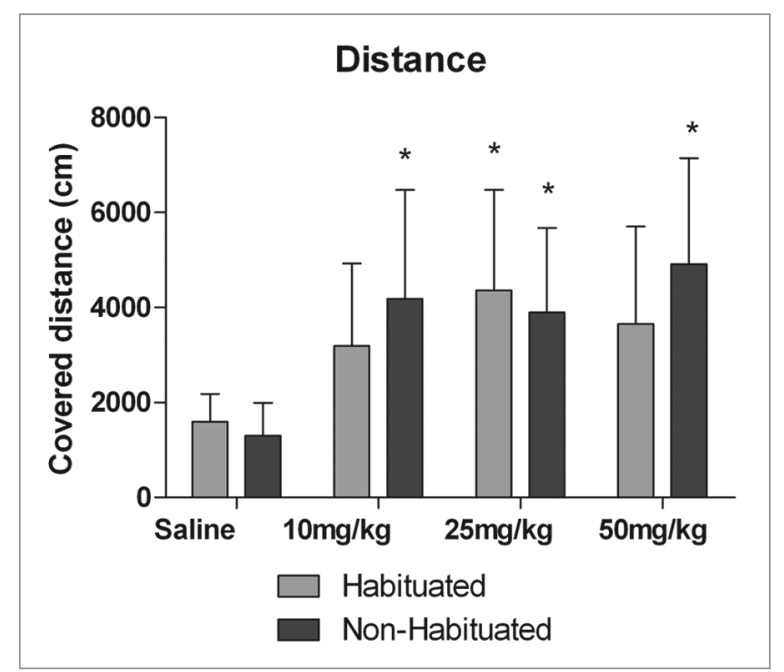

Figure 2. The open-field apparatus was used to assess locomotor activity and accumulated covered distance was measured in habituated and non-habituated rats to the open-field apparatus. The distance was analized by 60 minutes. Data were analyzed by ANOVA followed by Tuckey test. *A value of $p<0.05$ was considered significant and different from control. Results were expressed as centimeters $(\mathrm{cm})$.

are some evidence showing relevant biochemical and physiological abnormalities, including neuronal disorganization of the prefrontal cortex ${ }^{34}$ and a reduction in cortical volume. ${ }^{35}$ Alterations in $\gamma$-aminobutyric acid (GABA) neurons as well as dopaminergic $^{36}$ and glutamatergic alterations are also fundamental in the disease. $^{37}$

Habituation is one of the simplest ways to implicit learning and it is altered in schizophrenic patients, whom are capable to execute the routine tasks in a family place, but are not able to perform the same tasks in a different place..$^{38} \mathrm{~A}$ recent research showed that the subchronic treatment with sub-anesthetic doses of ketamine induces schizophrenia-related alterations. ${ }^{7}$ It has been also described cognitive and functional deficit such as alteration of declarative memory and surveillance. ${ }^{39}$

CK activity is an important energy reserve in tissues that need a high demand of energy. Some studies related a hypometabolic activity in prefrontal corte $\mathrm{x}^{40}$ and alterations in dopaminergic, cholinergic and serotoninergic neurotransmission. ${ }^{41}$ We can observe in this study that the CK activity is increased in all brain structures tested, suggesting that 25 and $50 \mathrm{mg} /$ $\mathrm{kg}$ may cause the increase of the energy demand to supply the necessity of ATP. Our study are in agreement with Littlewood et al. ${ }^{27}$ which demonstrated evidences that determine the temporal and spatial neuronal activation profile of ketamine in the rat brain by indentifying changes in blood-oxygenationlevel-dependent (BOLD) in different cerebral structures, using sub-anesthetic doses of 10 and $25 \mathrm{mg} / \mathrm{kg}$. Both doses revealed specific activations in prefrontal cortex, hippocampus and limbic areas, after the injection of sub-anesthetic dose of $25 \mathrm{mg} / \mathrm{kg}$ of ketamine. In this context, Oliveira et al..$^{42}$ observed that subanesthetic doses of ketamine at 4,10 and $30 \mathrm{mg} / \mathrm{kg}$, indicating an increase of lipid peroxidation, oxidative protein damage and decrease of enzymatic antioxidant defense. In this context, 


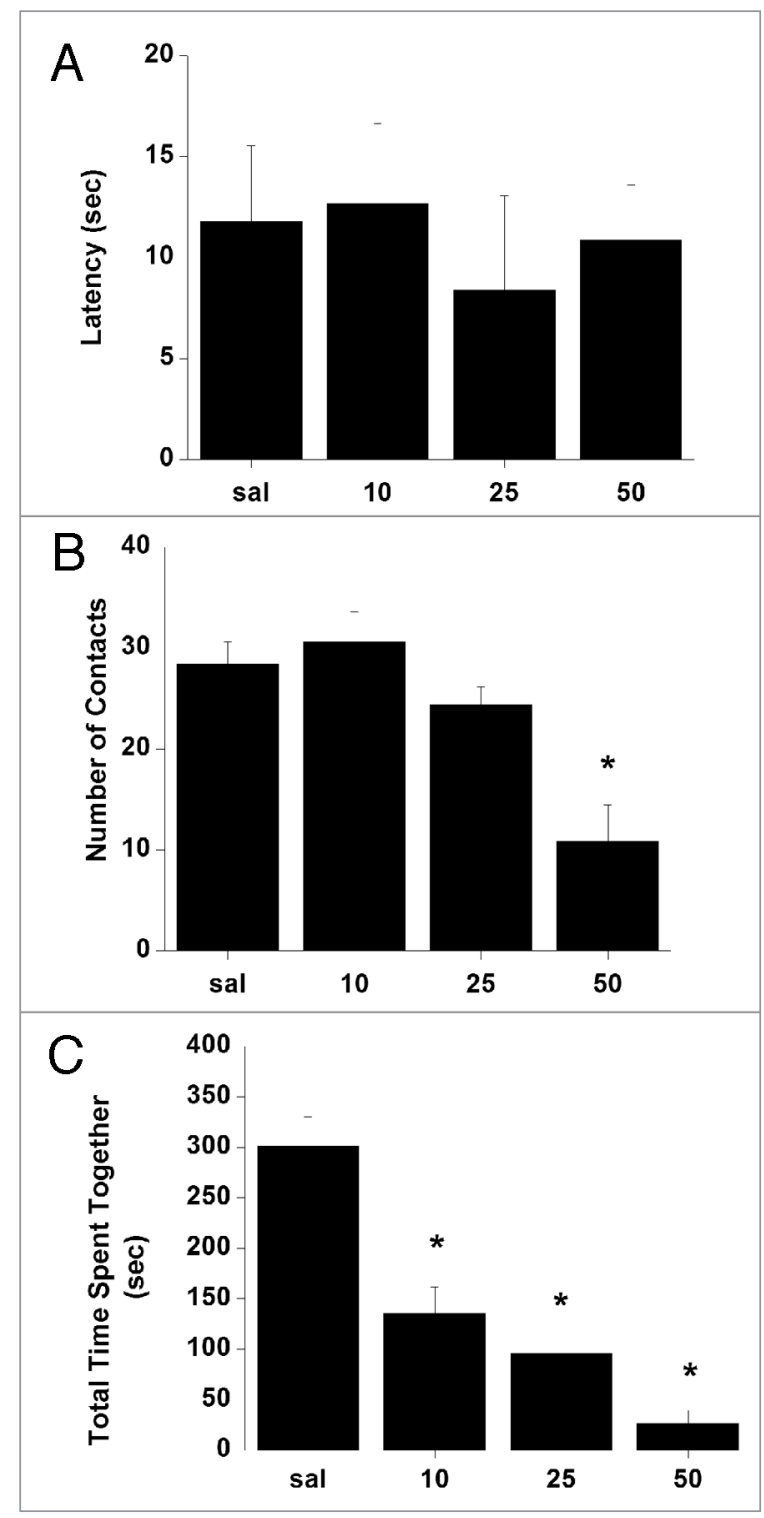

Figure 3. Impaired social behavioral is observed in ketamine treated animals. Social interaction was induced by different doses of ketamine and tested in unfamiliar conditions in an open field apparatus. Parameters analized were (A) Latency to start interacting; (B) number of contacts; (C) time spent engaged in social interaction 15 minutes after injection. Data were analyzed by one-way analysis of variance followed by Tukey test when $\mathrm{F}$ was significant. Values are expressed as mean \pm S.D., for ten animals in each group. *Different from control; $\mathrm{p}<0.01$.

other neurological disorders were already related with oxidative stress. $^{43,44}$

There are evidences relating hippocampal dysfunction in schizophrenia. ${ }^{45-48}$ Burbaeva et al. ${ }^{49}$ observed decreased in CK-BB immunoreactivity levels in hippocampus of schizophrenic patients. Our results also showed a significant increase in the CK activity caused by the administration of sub-anesthetic dose of 50 $\mathrm{mg} / \mathrm{kg}$ in habituated animals, suggesting a higher ATP demand probably due to hippocampal hyperactivity. Hippocampal hyperactivity might be an explanation for some symptoms found in schizophrenic patients, such as hallucinations and delusions. ${ }^{50}$
An imbalance in energy metabolism can produce free radicals and an increase of CK activity may show an increase of ATP demand, so oxidative stress can also be related to the disease progression. ${ }^{51}$ Studies in postmortem brain tissues have also demonstrated a possible role for mitogen-activated protein kinases (MAPKs) in schizophrenia. ${ }^{52}$ Although the caspase molecule is associated to apoptosis in the CNS, ${ }^{53}$ it has been shown in other studies that this molecule is upregulated in temporal cortex of subjects with schizophrenia, ${ }^{54}$ and these events are associated to dysregulation of CK activity in brain of schizophrenic patients. ${ }^{49}$

Animal models are attempted to mimic a human condition and many models have been used to simulate schizophrenic disorders. The mechanisms underlying the pathophysiology of schizophrenia are not completely understood. However we can state that $25 \mathrm{mg} / \mathrm{kg}$ of ketamine may be used as a model of schizophrenia. We also suggest that cerebral energy metabolism might be altered in the brain of schizophrenic patients, probably leading to drastic alterations that might be involved in the pathogenesis of schizophrenia.

\section{Methods}

Animals and reagents. Adult male Wistar rats (60 days-old) were obtained from Central Animal House of Universidade do Extremo Sul Catarinense. They were caged in group of five with free access to food and water and were maintained on a $12 \mathrm{~h}$ light-dark cycle (lights on 7:00 am), at a temperature of $22^{\circ} \mathrm{C} \pm 1^{\circ} \mathrm{C}$. All experimental procedures were carried out in accordance with the National Institutes of Health Guide for the Care and Use of Laboratory Animals and the Brazilian Society for Neuroscience and Behavior $(\mathrm{SBNeC})$ recommendations for animal care, with the approval of Ethics Committee from Universidade do Extremo Sul Catarinense.

Animal model of schizophrenia. The animals were injected with saline or 10, 25, $50 \mathrm{mg} / \mathrm{kg}$ ketamine (CU Chemie Uetikon, Germany) intraperitoneally (i.p.) at a volume of $1 \mathrm{~mL} / 100 \mathrm{~g}$.

Locomotor activity. We used the open-field task to assess locomotor activity. The task was performed in a $40 \times 60 \mathrm{~cm}$ open field surrounded by $50 \mathrm{~cm}$-high walls made of brown plywood with a frontal glass wall. The floor of the open field was divided into 12 equal rectangles by black lines. The animals were gently placed on the left rear rectangle and were allowed to explore the arena. Covered distance was counted for assessed for $60 \mathrm{~min}$ in an automatic arena.

Locomotor activity is constantly monitored by a system installed in an arena containing six parallel bars, each bar containing sixteen infrared sensors that detect rat's exact position and movement, making possible a detailed analysis of animal's behavior. Information detected by the sensors is transmitted to a computer in which animal's activity is recorded each five minutes by a software (data base: Open Sourse version Interbase 6.01). Distance covered by the animal is considered by the sum of the changes in position monitored by the activity arena, the software calculates the distance between two locations, plus the previously traveled distances. 
Both ketamine and saline groups where divided into habituated and non-habituated. Habituation is the interval in which animals are allowed to acknowledge and freely explore the testing environment. This is an important parameter for the animal to recognize the testing cage before data collection, reducing the anxiety during testing. Habituation time was considered 20 min before the injection, then, animals were injected with different doses of Ketamine and tested for 60 minutes after the injection. Non-habituated animals were injected with different doses of the compound and then gently placed in the activity arena.

Social interaction. Impaired social behavior is a key behavioral feature of rodent models of autism spectrum disorders and schizophrenia. ${ }^{55-58}$ Social interaction was tested in rats submitted to sub-anesthetic doses of ketamine $(10,25$ and $50 \mathrm{mg} / \mathrm{kg})$. For this task a total of 30 rats were tested under dim/light and unfamiliar conditions, in an open field apparatus. On the day of the experiment, the animals were socially isolated in plastic cages measuring $43 \times 28 \times 15 \mathrm{~cm}\left(\mathrm{l}_{-} \mathrm{w}_{-} \mathrm{h}\right)$ for $3.5 \mathrm{~h}$ prior to the experiment. This isolation period has been shown to produce a half maximal increase in the amount of social play. ${ }^{59}$ The task consisted in placing two animals from the same experimental group but from different cages into the test cage for $15 \mathrm{~min}$. Pairs were tested in a randomized order per groups and animals did not differ by more than $15 \mathrm{~g}$ in body weight. The social behavior was assessed for a pair of animals, so behavior of individual animals was not analyzed..$^{58}$ Latency to start social behavior (following or approaching the test partner, mounting or crawling over the test partner, sniffing or grooming any part of the body of the test partner), the total time spent engaged in social behavior and the number of social contacts were measured..$^{58,59}$

Stereotypy. Stereotypy was defined as rapid, repetitive head and forelimb movements. ${ }^{60,61}$ This parameter was analyzed at the same time and place as hyperlocomotor activity. Stereotypy is considered by the software as an instable movement any time when repetitive movements are recorded in sequel readings, without alteration in animal's mass center. The possible units of measurement to be considered are $\mathrm{mm}$ (millimeters), $\mathrm{cm}$ (centimeters) and in (inches).

Tissue and homogenate preparation. Animals were killed by decapitation 60 minutes after behavioral analyses. Brains were removed and prefrontal cortex, cerebellum, hippocampus, striatum and cerebral cortex were homogenized $(1: 10, w / v)$ in SETH buffer, pH 7.4 (250 mM sucrose, $2 \mathrm{mM}$ EDTA, 10 $\mathrm{mM}$ Trizma base, $50 \mathrm{IU} / \mathrm{ml}$ heparin).

Homogenates were centrifuged at $800 \mathrm{xg}$ for $10 \mathrm{~min}$ and the supernatants were kept at $-70^{\circ} \mathrm{C}$ until used for enzyme activity determination. Protein content was determined by the method described by Lowry et al. ${ }^{62}$ using bovine serum albumin as standard.

Creatine kinase activity. Creatine kinase activity was measured in brain homogenates pre-treated with $0.625 \mu \mathrm{M}$ lauryl

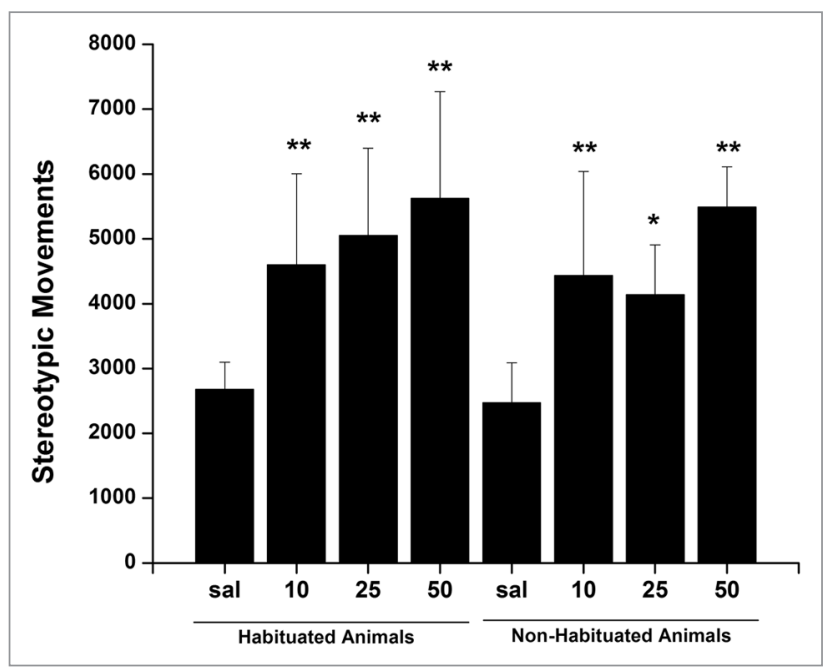

Figure 4. Stereotypic movements are considered as rapid, repetitive head and forelimb movements. It was induced by different doses of ketamine and analyzed 15 minutes after the injection. Data were analyzed by one-way analysis of variance followed by Tukey test when F was significant. Values are expressed as mean \pm S.D. for ten animals in each group. *Different from control; $p<0.01$. **Different to each other; $p<$ 0.01 . The units is millimeters $(\mathrm{mm})$, centimeters $(\mathrm{cm})$ and inches (in).
Figure 5. Creatine kinase activity. CK was measured by colorimetric method and the effect of sub-anesthetic doses of ketamine on this enzyme was verified in pre frontal cortex (PFC), cerebellum, hippocampus, striatum and total cortex. Control group is treated with saline $0.9 \%$. Data were analyzed by ANOVA followed by Tuckey test for six independent experiments (animals) performed in duplicate. ${ }^{*} A$ value of $p<0.05$ was considered significant and different from control. Results were expressed as $(\min \times \mathrm{mg} \text { protein })^{-1}$. maltoside. The reaction mixture consisted of $60 \mu \mathrm{M}$ Tris- $\mathrm{HCl}$, $\mathrm{pH} 7.5$, containing $7 \mu \mathrm{M}$ phosphocreatine, $9 \mathrm{mM} \mathrm{MgSO}_{4}$ and approximately $0.4-1.2 \mathrm{mg}$ protein in a final volume of $100 \mu \mathrm{L}$. After $15 \mathrm{~min}$ of pre-incubation at $37^{\circ} \mathrm{C}$, the reaction was started by the addition of $0.3 \mathrm{mmol}$ of ADP plus $0.08 \mu \mathrm{mol}$ of reduced glutathione. The reaction was stopped after $10 \mathrm{~min}$ by the addition of $1 \mu \mathrm{mol}$ of $\mathrm{p}$-hydroxymercuribenzoic acid. The creatine formed was estimated according to the colorimetric method 
of Hughes et al. ${ }^{63}$ The color was developed by the addition of $100 \mu \mathrm{L} 2 \% \mu$-naphtol and $100 \mu \mathrm{L} 0.05 \%$ diacetyl in a final volume of $1 \mu \mathrm{L}$ and read spectrophotometrically after $20 \mathrm{~min}$ at $540 \mathrm{~nm}$. Results were expressed as units (min x mg protein) ${ }^{-1}$.

Statistical analysis. Data were analyzed by one-way analysis of variance (ANOVA) followed by the Tukey multiple range test when the $\mathrm{F}$ was significant. All analyses were performed using the Statistical Package for the Social Sciences (SPSS). A value of $\mathrm{p}<0.05$ was considered to be significant.

\section{Acknowledgements}

This research was supported by grants from CNPq, FAPESC, Instituto Cérebro e Mente, INCT and UNESC to A.I.Z., E.L.S. and J.Q. (CNPq Research Fellows).

\section{References}

1. Stefan M, Travis M, Murray R. An atlas of schizophrenia. (The encyclopedia of visual medicine series), Part Publisc G London UK 2002.

2. Robertson GS, Hori SE, Powell KJ. Schizophrenia: an integrative approach to modelling a complex disorder. J Psychiatric Neurosci 2006; 31:157-67.

3. Bowie CR, Harvey PD. Schizophrenia from a Neuropsychiatric Perspective. Mt Sinai J Med 2006; 73:993-8.

4. Geyer MA, Moghaddam B. Animal models relevant to schizophrenia disorders. Neuropsychopharmacology: The Fifth Generation of Progress. In: Davis KL Dennis Charney D, Coyle JT, Nemeroff C. Am Coll Neuropsychopharmacol USA 2002.

5. Van den Buuse M, Garner B, Gogos A, Kusljic S. Importance of animal models in schizophrenia. Res Aust N Z J Psychiatric 2005; 39:550-7.

6. Trujillo KA, Zamora JJ, Warmoth KP. Increased responde to ketamine follwing treatment at long intervals: implications for intermittent use. Biol Psychiatry 2008; 63:178-83.

7. Becker A, Grecksch G. Ketamine-induced changes in rat behavior: a possibl animal model of schizophrenia. Test of predictive validity. Prog Neuropsychopharmacol Biol Psychiatry 2004; 28:1267-77.

8. Becker A, Peters B, Schroeder H, Mann T, Huether G, Grecksch G. Ketamine-induced changes in rat behaviour: A possible animal model of schizophrenia. Prog Neuropsychopharmacol Biol Psychiatric 2003; 27:687-700.

9. Ellison G. The N-methyl-d-aspartate antagonists phencyclidine, ketamine and dizocilpine as both behavioral and anatomical models of the dementias. Brain Res Bull 1995; 20:250-67.

10. Mattson MP, Gleichmann M, Cheng A. Mitochondria in neuroplasticity and neurobiological disorders. Neuron 2008; 60:748-66.

11. Goto Y. Mitochondrial dysfunction and brain development disorders. No To Shinkei 2001; 53:421-6.

12. Prince JA, Yassin MS, Oreland L. Neuroleptic-induced mitochondrial enzyme alterations in the rat brain. J Pharmacol Exp Ther 1997; 280:261-7.

13. Manfredi G, Beal MF. The role of mitochodrial in the pathogenesis of neurodegenerative diseases. Brain Pathol 2000; 10:462-72.

14. Kung L, Roberts RC. Mitochondrial pathology in human schizophrenic striatum: a postmortem ultrastructural study. Synapse 1999; 31:67-75.

15. Pieczenick SR, Neustadt J. Mitochondrial dysfunction and molecular pathways of disease. Exp Mol Pathol 2007; 83:84-92.

16. Wallimann T, Wyss M, Brdiczka D, Nicolay K, Eppenberger HM. Intracellular compartmentation, structure and function of creatine kinase isoenzymes in tissues with high and fluctuating energy demands: the phosphocreatine circuit' for cellular energy homeostasis. Biochem J 1992; 281:21-40.

17. Pilla C, Cardozo RFO, Dornelles PKB, Dutra-Filho CS, Wyse T, Angela TS, et al. Kinetic studies on the inhibition of creatine kinase activity by branched-chain $\alpha$-amino acids in the brain cortex of rats. I J Develop Neurosci 2003; 21:145-51.

18. Ben-Schachar D. The interplay between mitochondrial complex I, dopamine and Sp1 in schizophrenia. J Neural Transm 2009; 116:1383-96.
19. Karry R, Klein E, Ben-Shachar D. Mitochondrial complex I subunits expression is altered in schizophrenia: a postmortem study. Biol. Psychiatry 2004; 55:676-84.

20. Schlattner U, Forstner M, Eder M, Stachowiak O, Fritz-Wolf K, Wallimann T. Functional aspects of the $\mathrm{X}$-ray structure of mitochondrial creatine kinase: molecular physiology approach. Mol Cell Biochem 1998; 184:125-40.

21. Aksenov M, Aksenova MV, Payne RM, Trojanovski JQ, Schmidt KL, Carney JM, et al. Oxidation of cytosolic proteins and expression of creatine kinase $\mathrm{BB}$ in frontal lobes of neurodegenerative disorders. Dement Geriatr Cogn Disord 1999; 10:158-65.

22. Freitas TP, Scaini G, Côrrea C, Santos PM, Ferreira GK, Rezin GT, et al. Evaluation of brain creatine kinase activity in an animal model of mania induced by ouabain. J Neural Transm 2010; 117:149-53.

23. Lewis DA, Lieberman JA. Catching up on schizophrenia: natural history and neurobiology. Neuron 2000; 28:325-34

24. Covington MA, Riedel WJ, Brown B, He C, Morris E, Weinstein S, et al. Does ketamine mimic aspects of schizophrenic speech? J Psychopharmacol 2007; 21:338-46

25. Garcia LS, Comim CM, Valvassori SS, Réus GZ, Andreazza AC, Stertz L, et al. Chronic administration of ketamine elicits antidepressant-like effects in rats without affecting hippocampal brain-derived neurotrophic factor protein levels. Basic Clin Pharmacol Toxicol 2008; 103:502-6.

26. Rezin GT, Gonçalves CL, Daufenbach JF, Fraga DB Santos PM, Ferreira GK, et al. Acute administration o ketamine reverses the inhibition of mitochondrial respiratory chain induced by chronic mild stress 2009; 79:418-21.

27. Littlewood CL, Jones N, O'Neill MJ, Mitchell SN Tricklebank M, Williams SC. Mapping the central effects of ketamine in the rat using pharmacological MRI. Psychopharmacol 2006; 188:261-72.

28. Hunt MJ, Raynaud B, Garcia R. Ketamine dosedependently unduces high-frequency oscillations in the nucleus accumbens in freely moving rats. Biol Psychiat 2006; 60:1206-14.

29. Jang HS, Choi HS, Lee SH, Jang KH, Lee MG. Evaluation of the anaesthetic effects of medetomidine and ketamine in rats and their reversal with atipamezole. Vet Anaesth Analg 2009; 36:319-27.

30. Pfenninger E, Himmelseher S. Neuroprotection by ketamine at the cellular level. Anaesthesist 1997; 46:47-54.

31. Rudin M, Ben-Abraham R, Gazit V, Tendler Y, Tashlykov V, Katz Y. Single-dose ketamine administration induces apoptosis in neonatal mouse brain. J Basic Clin Physiol Pharmacol 2005; 16:231-43.

32. Irifune M, Sato T, Kamata Y, Nishikawa T, Nomoto M, Fukuda T, et al. Inhibition by diazepam of ketamineinduced hyperlocomotion and dopamine turnover in mice. Can J Anaesth 1998; 45:471-8.

33. Ridley RM. The psychology of perseverative and stereotyped behaviour. Prog Neurobiol 1994; 44:221-31.

34. Uranova N, Orlovskaya D, Vikhreva O, Zimina I, Kolomeets N, Vostrikov V, et al. Electron microscopy of oligodendroglia in severe mental illness. Brain Res Bull 2001; 55:597-610.

35. Zipursky RB, Lim KO, Sullivan EV, Brown BW, Pfefferbaum A. Widespread cerebral gray matter vol ume deficits in schizophrenia 1992; 49:195-205.
36. Toda M, Abi-Dargham A. Dopamine hypothesis of schizophrenia: making sense of it all. Curr Psychiatric Rep 2007; 9:329-36.

37. Tsai G, Coyle TJ. Glutamatergic mechanismos in schizophrenia. Annu Rev Pharmacol Toxicol 2002; 42:165-79.

38. Velligan DL, Bow-Thomas CC. Executive function in schizophrenia. Semin Clin Neuropsychiatry 1999; 4:24-33.

39. Green JF, McElholm A, King DJ. A comparison of the sedative and amnestic effects of chlorpromazine and lorazepam. Psychopharmacol 1996; 128:67-73.

40. Kasai K, Iwanami A, Yamasue H, Kuroki N, Nakagome K, Fukuda M. Neuroanatomy and neurophysiology in schizophrenia. Neurosc Res 2002; 43:93-110.

41. Bertolino A. Dysregulation of dopamine and pathology of prefrontal neurons: neuroimaging studies in schizophrenia and related animal models. Epidemiol Psichiatr Soc 1999; 8:248-54

42. Oliveira L, Spiazzi CM, Bortolin T, Canever L, Petronilho F, Mina FG, et al. Different sub-anesthetic doses of ketamine increase oxidative stress in the brain of rats. Prog Neuropsychofarmacol Biol Psychiatry 2009; 33:1003-8.

43. Santos IM, Tomé Ada R, Saldanha GB, Ferreira PM, Freitas RM. Oxidative stress in the hippocampus during experimental seizures can be ameliorated with the antioxidant ascorbic acid. Oxid Med Cell Longev 2009; 2:214-21.

44. Bouayed J, Rammal H, Soulomani R. Oxidative stress and anxiety: Relationship and cellular pathways. Oxid Med Cell Longev 2009; 2:63-7.

45. Harrison PJ. The hippocampus in schizophrenia: review of the neuropathological evidence and its pathophysiological implications. Pychopharmacol 2004; 174:151-62.

46. Meyer J, Huberth A, Ortega G, Syagailo YV, Jatzke $\mathrm{S}$, Mossner $\mathrm{R}$, et al. A missense mutation in a novel gene encoding a putative cation channel is associated with catatonic schizophrenia in a large pedigree. $\mathrm{Mol}$ Psychiatric 2001; 6:302-6.

47. Weiss AP, Goff D, Schacter DL, Ditman T, Freudenreich $\mathrm{O}$, Henderson D, et al. Fronto-hippocampal function during temporal context monitoring in schizophrenia. Biol Psychatric 2006; 60:1268-77.

48. Shenton ME, Dickey CC, Frumin M, McCarley RW. A review of MRI findings in schizophrenia. Schizophr Res 2001; 49:1-52.

49. Burbaeva GS, Savushkina OK, Boksha IS. Creatine Kinase BB in Brain in Schizophrenia. Worl J Biol Psychiatric 2003; 4:177-83.

50. Venables PH. Hippocampal function and schizophrenia. Experimental psychological evidence. Ann NY Acad Sci 1999; 658:111-27.

51. Reddy R, Keshavan MS. Phosphrus magnetic resonance spectroscopy: its utility in examining the membranes hypothesis of schizophrenia. Prostaglandins Leukot E Fat Ac 2003; 69:401-5.

52. Kyosseva SV, Elbein AD, Griffin WS, Mrak RE, Lyon $\mathrm{M}$, Karson CN. Mitogen-activated protein kinases in schizophrenia. Biol Psychiatry 1999; 46:689-96.

53. Yuan J, Yankner BA. Apoptosis in the nervous system. Nature 2000; 407:802-19.

54. Jarskog LF, Selinger ES, Lieberman JA, Gilmore JH. Apoptotic proteins in the temporal cortex in schizophrenia: high $\mathrm{Bax} / \mathrm{Bcl}-2$ ratio without caspase- 3 activation. Am J Psychiatry 2004; 161:109-15. 
55. Mohn AR, Gainetdinov RR, Caron MG, Koller BH. Mice with reduced NMDA receptor expression display behaviors related to schizophrenia. Cell 1999; 98:427-36.

56. DiCicco-Bloom E, Lord C, Zwaigenbaum L, Courchesne E, Dager SR, Schmitz C, et al. The developmental neurobiology of autism spectrum disorder. J Neurosc 2006; 26:6897-906.

57. Moldin SO, Rubenstein JL, Hyman SE. Can autism speak to neuroscience? J Neurosc 2006; 26:6893-6.

58. Schneider T, Przewlocki R. Behavioral alterations in rats prenatally exposed to valproic acid: animal model of autism. Neuropsychopharmacol 2005; 30:80-9.

59. Niesink RJM, Van Ree JM. Involvement of opioid and dopaminergic systems in isolation-induced pinning and social grooming of young rats. Neuropharmacol 1989; 28:411-8
60. Hitri A, O'Connor DA, Cohen JM, Keuler DJ Deutsch SI. Differentiation between MK-801- and apomorphine-induced stereotyped behaviors in mice. Clin Neuropharmacol 1993; 16:220-36.

61. Battisti JJ, Shreffler CB, Uretsky NJ, Wallace LJ. NMDA antagonists block expression of sensitization of amphetamine-and apomorphineinduced stereotypy. Pharmacol Biochem Behav 2000; 67:241-6.

62. Lowry $\mathrm{OH}$, Rosebrough NJ, Farr AL, Randall RJ. Protein measurement with the Folin phenol reagent. J Biol Chem 1951; 193:265-7.

63. Hughes BP. A method for estimation of serum creatine kinase and its use in comparing creatine kinase and aldolase activity in normal and pathologic sera. Clin Chim 1962; 7:597-604. 


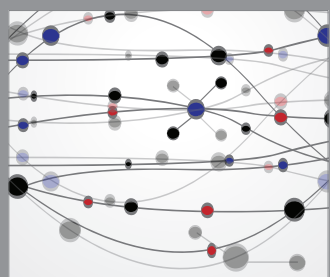

The Scientific World Journal
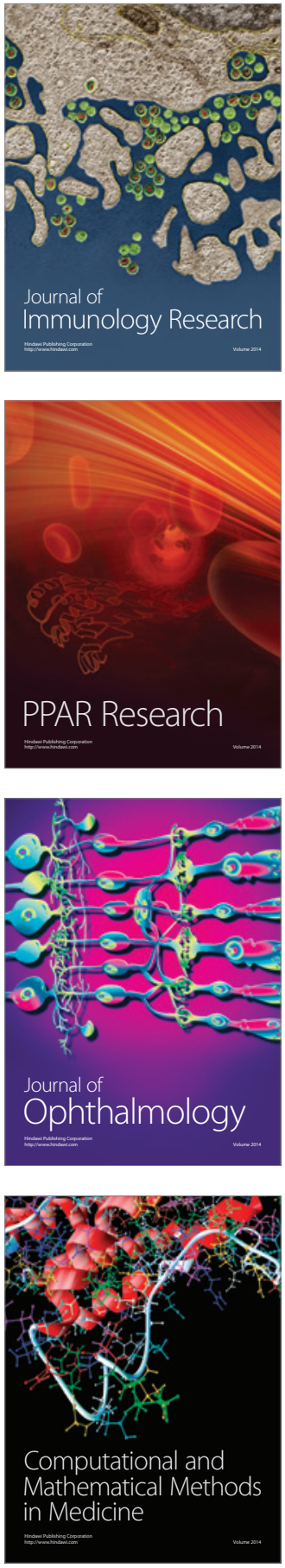

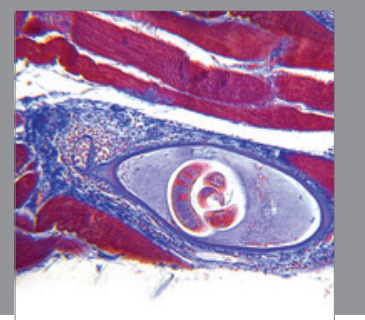

Gastroenterology

Research and Practice
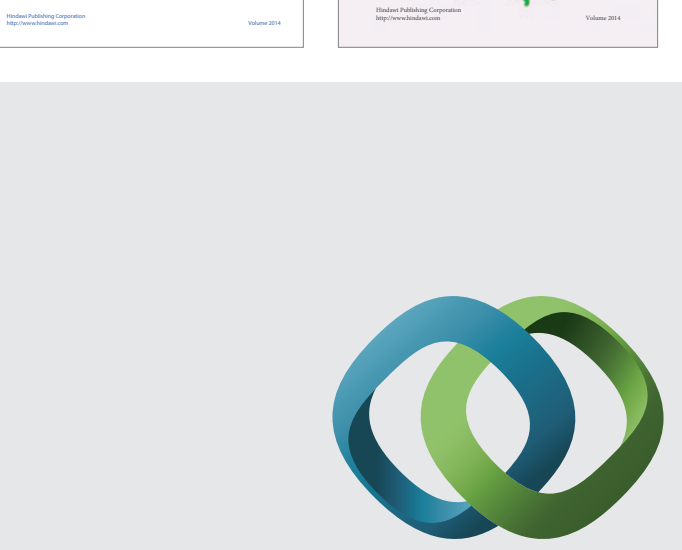

\section{Hindawi}

Submit your manuscripts at

http://www.hindawi.com
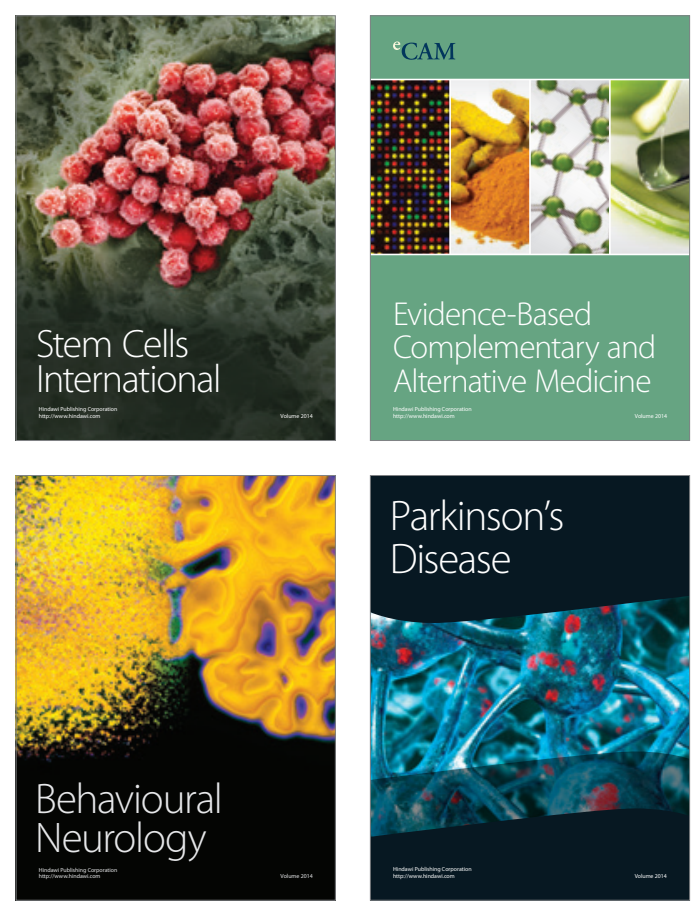

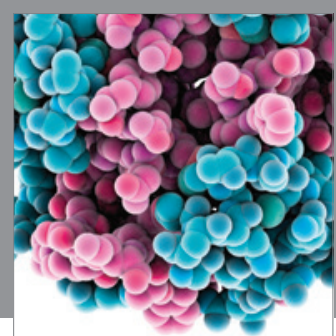

Journal of
Diabetes Research

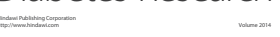

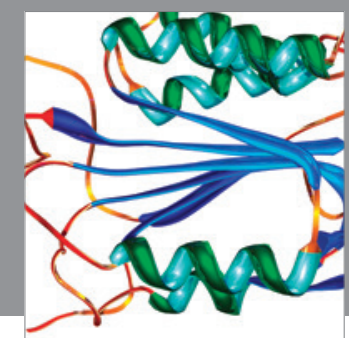

Disease Markers
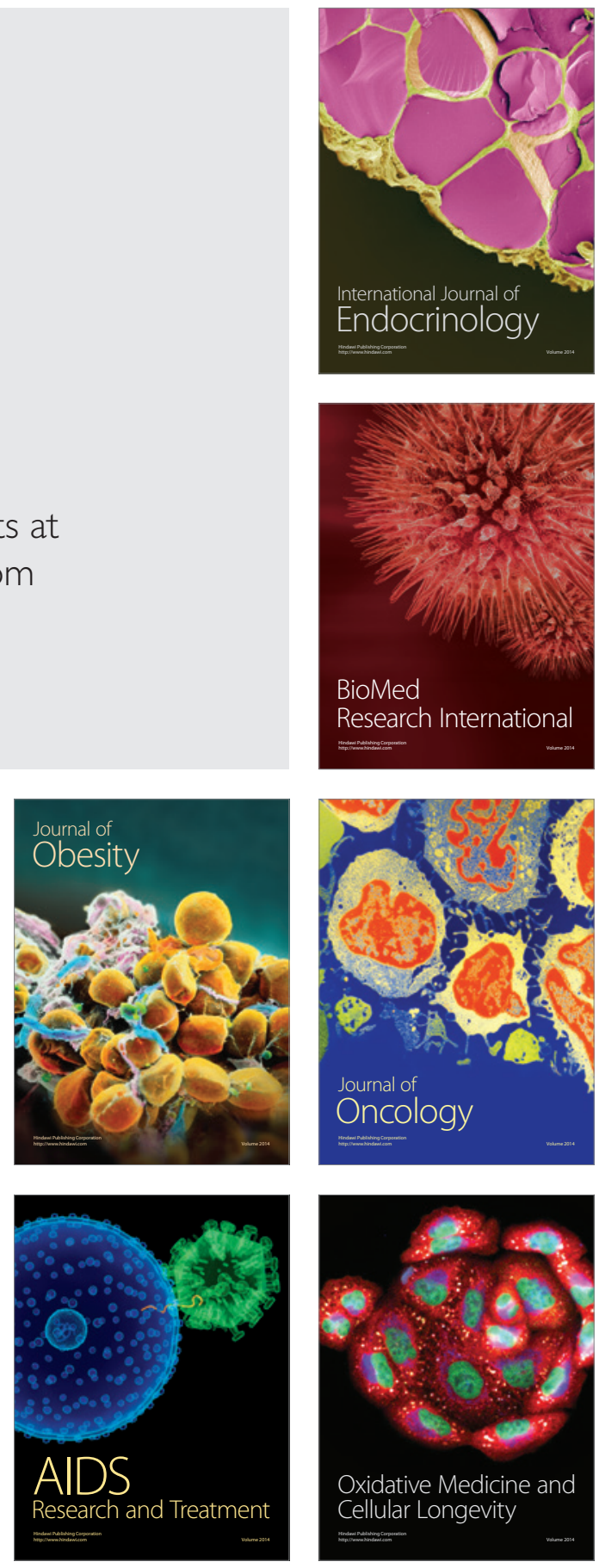